\title{
Research on the Characteristics and Orientation development of Folk Sports Industry based on "Point axis" theory
}

Yali Li

Lanzhou resources and environment Vocationsl technology college 730000

Li Yali Female October, 1984,

Han Nationality Native place: Tianshui Gansu Work: Lanzhou resources and environment Vocationsl technology college

Zip code 730000

Educational background: University degree Title: Lecturer

Research direction: Sports economy

Topic information: Gansu Province sports bureau topic

Project name: Silk Road economical belt" Gansu gold section region characteristic sports industry development research

The project numbers GST22019136

Lanzhou social science planning project: Silk Road economical belt" Gansu gold section region characteristic sports industry development research—_ Take the Lanzhou city as the example

Project serial number: 19-024E

Abstract: With the deepening of China's modernization, people's pursuit of healthy life is also constantly improving, so the development of folk sports is the current need to pay attention to an industry. This paper mainly discusses the characteristics and positioning development of folk sports industry based on the "point axis" theory. According to relevant data and investigation, the current development status of folk sports industry is understood, and the existing problems are sorted out. Then, based on the "point axis" theory, positive and effective development strategies are summarized. So as to promote the integration and development of folk sports industry and promote the continuous progress of China's health cause.

Keywords: "point axis" theory, folk sports, industrial characteristics, positioning development

In recent years, the state's investment in the cause of health is constantly increasing, the construction of a healthy China needs the strength of all sectors of society, from the state to individuals need to actively participate in, cooperative development. Folk sports are different from ordinary sports industry, with certain regional characteristics, which can not only enrich people's life but also promote the emotion between nationalities. Economic development and social progress have brought more and more scientific development theories, and the "point axis" theory has been gradually widely applied to all aspects of social construction, which is to gradually drive the progress and development of the whole region by connecting points.

\section{Overview of the development of folk sports industry}

\subsection{Development status of folk sports industry}

Our country has a vast territory and abundant resources, with 56 ethnic groups, and the cultures and customs of

Copyright (C) 2020 Yali Li

doi: 10.18282/le.v9i5.1199

This is an open-access article distributed under the terms of the Creative Commons Attribution Non-Commercial License

(http://creativecommons.org/licenses/by-nc/4.0/), which permits unrestricted non-commercial use, distribution, and reproduction in any medium, provided the original work is properly cited. 
different regions are very different, because

There are various cultural marks on the inheritance of folk culture. Influenced by the development of politics, economy, culture and education, folk sports activities gradually sprout and grow in different regional environments, and these folk sports activities can well meet the beliefs, customs and concepts of local people. Folk activities have their own vitality, in the continuous progress and development of the society folk sports activities are also developing slowly. Different regions have rich and different folk sports activities, such as the folk bamboo float in northern guizhou, crossbow shooting in yunnan-guizhou guangxi region, wrestling, gyro, flower drum lamp, dragon and lion dancing, etc. These folk sports industries all have distinct characteristics. But due to the development of the economy and the advance of information technology, the Internet is widely used gradually, so more and more people spend time on the Internet, folk sports industry has been a certain impact, people's demands of the folk sports industry are also changing, need timely to recognize the problem and find a reasonable solution, to promote the sustainable development of folk sports industry in China.

\section{Problems existing in the development of folk sports industry}

At present, with the research and investigation, it can be understood that there are some problems in the development process of folk sports industry, in order to promote

In the scientific development of health cause and folk sports industry in China, we must grasp the problem and make reasonable improvement. First of all, in the development process of folk sports industry, there is a lack of historical inheritance. With the continuous advancement of globalization, diversified cultures and ideas are also constantly impacting traditional culture and customs, and many new sports and health activities emerge as The Times require. As the folk sports industry itself has a certain mythological color, and the procedures are relatively complicated. Secondly, more and more young people tend to accept the emerging sports and fitness activities, so the inheritance of folk sports industry in many regions is lacking. Secondly, people's mode of production is becoming more and more scientific. However, some folk sports activities have obvious traditional colors and are a hope for the low level of production mode. Therefore, with the change of production mode, some folk sports activities are gradually going far away. In addition, the transformation of cultural connotation also affects the development of folk sports industry. People's thoughts and consciousness are constantly improving, so it has a negative impact on folk sports industry with certain traditional cultural connotation and thought. Moreover, folk sports activities need the guidance of relevant personnel and the need of funds, but the number of folk sports activities in many areas is constantly decreasing due to the lack of funds. These are the problems encountered in the development of China's folk sports industry, which must be improved according to the actual situation of China's development, through a reasonable way to develop the folk sports industry.

Secondly, research on the characteristics and orientation development of folk sports industry based on the "point axis" theory

Different regions have different cultures and customs. Under such a background, the folk sports industry is in the process of development

The local characteristics should be fully combined with the rational use of them, so as to effectively promote the development of folk sports industry. Therefore, in the current society, the scientific development of folk sports industry can be promoted according to the "point axis" theory. Firstly, a good point axis development model should be constructed according to the inheritance status and cultural background of folk sports industry in the region. For the development of folk sports industry limited resources, so it can be in the process of the development of all resources together, and to distribute resources is preferred to have certain folk sports industry in the development of core area, focus on parts, again through the core area to drive around the development of folk sports industry, promote the progress of the overall health. For example, in some regions rich in natural resources, the developed resources can be invested into the folk sports industry that can reflect the natural resources and cultural atmosphere, and the regional characteristics can drive the overall development, so that the folk sports industry can come into the public's vision.

Secondly, in the process of actual development of folk sports industry, relevant knowledge based on the "point axis" theory can be used to drive the development and innovation of folk sports industry with the help of the driving 
force of relevant industries. Nowadays, various kinds of modern activities emerge in endlessly, so many folk sports activities show the form and connotation of folk sports activities to more and more people through the lens. From many TV programs, we learn more about the regional characteristic folk sports activities, which not only gives us a deeper understanding of this region, but also gives us a further feeling of the charm of China's rich folk sports industry. Such events have a positive impact on the folk sports industry. Through the integration of relevant resources and the transformation of operation mode, the folk sports industry can be combined with the publicity means of the new era, so as to enhance the core competitiveness of the folk sports industry. In addition, reasonable marketing communication means should be adopted to gradually drive the development of folk sports industry by connecting points, so as to create a healthy folk sports industry. You should first to the region's folk sports industry in the integration of the folk customs and culture connotation characteristics in this area has a deep understanding, reasonable packaging and publicity, again through the proper propaganda of regional folk sports industry, which help to form a certain brand agglomeration effect of institution transference into a steady development.

\section{Endnotes}

To sum up, the application of "point axis" theory can well promote the healthy development of folk sports industry, which is now widely accepted in modern times

The influence of the process of modernization, the new cultural trend of thought and the application of Internet information technology have a certain impact on the folk sports industry. Therefore, the limited resources of each region should be invested into the areas with good development of folk sports industry. Combined with regional characteristics, the strength and charm of folk sports industry should be increased, so as to drive the development of surrounding areas and finally achieve the comprehensive and healthy development of folk sports industry.

\section{References}

1. Ma Jianguo, Cheng Xinquan. Research on expansion Strategy of Folk Sports Tourism Industry [J]. Journal of Yulin University, 2019(6): 108-112

2. Sun Dongqi, Liu Weidong, Chen Mingxing. The Proposal of point-axis System Theory and its Application in China's Practice [J]. Economic Geography, 2016(3): 1-8 